\title{
Retraction Note to: Thermodynamic study on the interaction of cyanide ion and jack bean urease at different temperatures
}

\section{G. Rezaei Behbehani - A. A. Saboury •}

M. Mohebbian · J. Abedini - S. Tahmasebi Sarvestani
Retraction Note to: J Therm Anal Calorim (2010) 100:1079-1083

DOI 10.1007/s10973-009-0384-x

This article has been retracted by the Publisher and the Editor-in-Chief due to duplicate publication of data and text. It was determined that portions of this article significantly overlap with the paper published in the Journal of Solution Chemistry DOI 10.1007/s10953-009-9471-7. Many sentences in the two papers are identical or differ in only a minor way because of style differences between the two journals.

The online version of the original article can be found under doi:10.1007/s10973-009-0384-x.

G. Rezaei Behbehani $(\bowtie)$

Chemistry Department, Imam Khomeini International

University, Qazvin, Iran

e-mail: grb402003@yahoo.com

\author{
A. A. Saboury \\ Institute of Biochemistry and Biophysics, University of Tehran, \\ Tehran, Iran \\ M. Mohebbian · J. Abedini - S. Tahmasebi Sarvestani \\ Chemistry Department, Payame Noor University (PNU), Abhar, \\ Iran
}

